\title{
Peter Hänni: Rosas Blut (3)
}

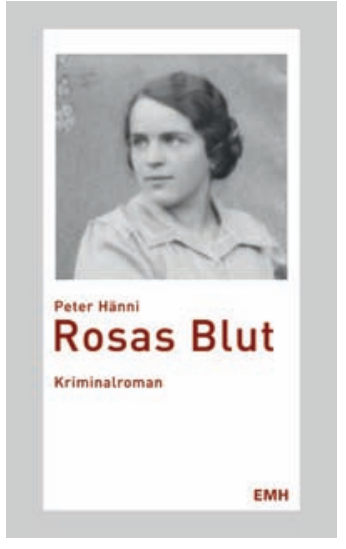

Peter Hänni

Rosas Blut

EMH Schweizerischer Ärzteverlag

Kriminalroman

2008. 192 Seiten. Broschiert.

Fr. 21.50 / € 14.80

exkl. Versand

ISBN 978-3-0375-033-6

Genau in dem Moment, als Salvatores Lippen die Stirn des Toten berührten, ertönte aus dem Sarg ein die Stille jäh durchschneidender Pfeifton! Luca und die übrigen Anwesenden fuhren erschrocken zusammen und wurden Zeugen, wie Salvatore entsetzt vom Sarg zurücktaumelte, über einen der leeren Stühle stolperte und mit einem Aufschrei zu Boden fiel. Luca sprang hoch und stürzte zu seinem Vater.

«Um Gottes willen! Hast du dir weh getan?» «Nein, nein, mir fehlt nichts», wiegelte der verdutzt am Boden sitzende Salvatore ab. «Alles in Ordnung!» Und in ängstlichem Flüsterton fuhr er fort: «Aber was zum Teufel war das für ein Pfeifen? Gerade als ich ... hast du es auch gehört?»

«Ja», antwortete Luca und nickte ein paarmal mit geschlossenen Augen. «Ich weiß zwar nicht, was es war, aber ich bin beinahe zu Tode erschrocken!»

Aufgeschreckt durch den Tumult, waren in der Zwischenzeit auch die anderen Trauergäste aus den Nebenräumen ins Zimmer gestürzt und hatten sich um Salvatore und Luca versammelt. Jemand hatte das Licht angeknipst, so dass der Raum vollständig erhellt war. Es herrschte ein Durcheinander, und aus dem Stimmengewirr stach das laute Jammern Lauras hervor, die über die ungebührliche Störung der Totenruhe ihres Gatten entsetzt war und sich fortwährend bekreuzigte. Luca und Francesco halfen Salvatore auf die Beine und führten ihn hinaus in die Küche, wo sie den immer noch verstörten Mann auf einen Stuhl setzten. Auch die übrigen Anwesenden verließen das Aufbahrungszimmer, nur
Laura blieb zurück, und durch die verschlossene Türe war immer noch ihr Wehklagen zu hören.

«Was war los da drin?», wollte Francesco wissen, und es war ihm anzumerken, dass auch er verärgert war.

Luca erzählte, was er beobachtet hatte. Danach herrschte Stille. Man schaute sich an, erstaunt und ratlos zugleich. Niemand sagte ein Wort, bis Salvatore mit brüchiger Stimme das Schweigen brach.

«Es war unheimlich ... ich konnte nichts dafür ... ich bin einfach erschrocken und dann gestolpert ... tut mir leid, Francesco, ich wollte nicht ...»

«Schon gut, Onkel Salvatore, schon gut. Reg dich nicht auf!» Francesco schien besänftigt und legte dem alten Mann die Hand auf die Schulter. «Dich trifft keine Schuld!»

Wieder herrschte betretenes Schweigen. Die in der Küche dichtgedrängten Menschen schienen angestrengt über das bizarre Ereignis nachzudenken. Luca betrachtete ihre Gesichter und war sicher, dass sich hinter der einen oder anderen eingeschüchterten Miene die Überzeugung breitmachte, dass man es hier mit einem übersinnlichen Phänomen zu tun hatte. Doch lange konnten sie nicht spekulieren, denn aus dem Aufbahrungszimmer ertönte wieder ein Schrei. Sekunden später sprang die Tür auf, und Laura kam mit schreckensweiten Augen herausgestürzt.

Leichenblass und mühsam nach Worten ringend berichtete sie über ein erneutes Pfeifen, das genau in dem Moment ertönt sei, als sie sich zu Carlo in den Sarg hinunterbückte. Etliche Gäste verließen daraufhin fluchtartig die Wohnung.

Eine Viertelstunde später saßen die noch Verbliebenen ratlos in der Küche. Filomena, Lauras Schwägerin, hatte frischen Kaffee zubereitet und stellte die eiserne Kanne auf den rustikalen Holztisch, auf dem bereits Tassen, Schnapsgläser, eine Zuckerdose und eine etikettenlose Flasche mit wasserklarer Flüssigkeit standen.

«Sollten wir nicht Dottore Palatucci oder den Leichenbestatter rufen?», schlug Filomena zaghaft vor, während sie begann, den aromatisch duftenden Kaffee einzuschenken. «Vielleicht hat einer von ihnen eine Erklärung für das unheimliche Geräusch.»

«Gute Idee!», stimmte Francesco zu und schickte sich an, die Schnapsgläser zu füllen. «Was meinst du, Mama?»

\section{Rosas Blut - ein Kriminalroman bei EMH}

Mit «Rosas Blut» von Peter Hänni erweitert der Schweizerische Ärzteverlag EMH sein Buchprogramm um die Sparte Kriminalroman. Leserinnen und Leser der SÄZ können sich von den Qualitäten des Romans anhand einer Leseprobe in vier Teilen überzeugen - und sie haben die Möglichkeit, das Buch direkt beim Verlag zu bestellen: online unter www.emh.ch/books oder über Tel. 06146785 75. Ein Artikel von Erhard Taverna zu Autor und Werk ist in der SÄZ

Nr. 40/2008 erschienen.
«Ich denke, das wird nicht nötig sein!», antwortete Laura nach einigem Zögern, den Blick auf ihren Schoß gerichtet, wo sie nervös an einem Taschentuch herumnestelte.

«Wieso nicht?», fragte Francesco erstaunt. «Willst du nicht wissen, was los war?»

«Ich weiß es doch!», erwiderte sie trotzig und blickte in eine Runde verdutzter Gesichter. «Na ja ... zumindest glaube ich es zu wissen.»

Reglos und voller Erwartung starrten alle auf die Frau, die ihren Blick wieder senkte und das Taschentuch bearbeitete.

«Ja ... so sprich doch endlich, um Gottes willen!», platzte es grob aus Francesco heraus, als seine Mutter keine Anstalten machte, sie aufzuklären.

«Die Hörgeräte!», sagte sie leise. «Was?! Welche Hörgeräte?», rief Francesco ungläubig und begriff ebenso wenig wie die anderen, was seine Mutter meinte. Nur Luca verstand, worauf Laura hinauswollte.

«War Onkel Carlo Hörgeräteträger?», fragte er ruhig. «Seit zwei oder drei Wochen, ja. Er hatte schon seit Jahren Probleme. Der Fabriklärm hat sein Gehör kaputtgemacht. Vor kurzem hat er sich endlich dazu durchgerungen, einen Versuch mit diesen neuen Geräten zu wagen, diesen kleinen, die man in den Gehörgang einsetzen kann und von außen kaum sieht. Er wollte nicht, dass sie für jedermann erkennbar waren.»

«Hat man sie heute nicht herausgenommen?», wollte Luca wissen.

«Ich jedenfalls nicht», gab Laura kleinlaut zur Antwort. «Bis vorhin habe ich gar nicht an die blöden Dinger gedacht. Und sonst wusste ja niemand davon.»

Die anderen begriffen immer noch nicht, und so erklärte Luca ihnen, dass Hörgeräte ein Rückkopplungspfeifen verursachen, wenn sie nicht richtig im Ohr sitzen oder wenn ein Gegenstand von außen in die Nähe des Gehörganges herangeführt wird. Dies sei ein normales Phänomen. Dadurch, dass sich sein Vater und Laura zu Carlo hinuntergebeugt hätten, seien sie in die Nähe der Ohren gekommen, was offensichtlich ausgereicht habe, um diesen Rückkopplungseffekt auszulösen.

Also doch keine übersinnliche Erscheinung! Ein banales technisches Phänomen hatte die ganze Aufregung verursacht. In der Runde machte sich Erleichterung breit. 